\title{
PERCEPÇÃO DE EDUCADORES DE ABRIGO: O SEU TRABALHO E A CRIANÇA INSTITUCIONALIZADA
}

\author{
THE PERCEPTION OF SHELTER CARE EDUCATORS: \\ THEIR WORK AND THE INSTITUTIONALIZED CHILD
}

\author{
Celina Maria Colino Magalhães ${ }^{1}$, Lígia Negrão Costa², \\ Lília Iêda Chaves Cavalcante ${ }^{3}$
}

\begin{abstract}
RESUMO:
Este artigo objetiva analisar a percepção de cuidadores de abrigo acerca do trabalho desenvolvido por eles e sobre as crianças institucionalizadas. Foram aplicados questionários a 102 educadoras do maior abrigo de Belém, entre 2004 e 2006. Os resultados mostraram que para os educadores: o atendimento da instituição é satisfatório com cuidados físicos básicos, mas não com questões afetivas e intelectuais; a criança institucionalizada não possui liberdade de fazer escolhas, não tem privacidade, nem atenção individualizada; o trabalho desses profissionais exerce pouca influência sobre o desenvolvimento cognitivo e afetivo infantil. Essas informações podem ser úteis na elaboração do projeto político pedagógico da instituição, enfatizando a unidade entre cuidar e educar.
\end{abstract}

Palavras-chave: criança; abrigo.

\begin{abstract}
:
The aim of this article is to study the perception of shelter care educators regarding the work performed by them as well as their effect on the institutionalized children under their care. Questionnaires were administered to 102 educators working in the largest shelter care facility in Belem during the period from 2004 to 2006. The results indicated that in the educator's view, in general service was satisfactory, and whereas basic physical needs were being met, provisions for affective and intellectual growth were not adequate. In particular, children in these facilities had little privacy, nor were they afforded sufficient individual attention. Furthermore, the educator's work appeared to exert minimal influence on the children's cognitive and emotional development. Such information may be useful for formulating more effective pedagogical policies, emphasizing a more integrated link between child care and education.
\end{abstract}

Key words: children; child care.

1 Professora Dra do Programa de Pós-graduação em Teoria e Pesquisa do Comportamento, UFPA. Rua Augusto Corrêa, 01 - Guamá. CEP 66075-110. Bolsista de Produtividade em Pesquisa CNPq.

2 Terapeuta Ocupacional, mestranda do Programa de Pós-graduação em Teoria e Pesquisa do Comportamento, UFPA, Bolsista CAPES. Av. Dalva, no 537. Marambaia. CEP 66615-850.

3 Professora Dra do Programa de Pós-graduação em Teoria e Pesquisa do Comportamento, UFPA. Rua Padre Eutíquio, no 1922, apto 2300. Batista Campos - CEP 66033-000.

Correspondência para: liliaccavalcante@gmail.com.

Trabalho realizado no Espaço de Acolhimento Provisório Infantil (EAPI), vinculado à Secretaria de Estado de Assistência e Desenvolvimento Social (SEDES) do Governo do Estado do Pará.

Baseado na Tese de Doutorado: Cavalcante, LIC. Ecologia do Cuidado: interações entre a criança, o ambiente, os adultos e seus pares em instituições de abrigo. 2008. Programa de Pós-graduação em Teoria e Pesquisa do Comportamento, Universidade Federal do Pará. Orientadora: Celina Maria Colino Magalhães.

Como citar este artigo: Magalhães CMC, Costa LN, Cavalcante LIC. The perception of shelter care educators: their work and the institutionalized child. Journal of Human Growth and Development 2011; 21(3): 818-831.

Artigo submetido em 19.02.11, aceito em 10.08.11. 


\section{INTRODUÇÃO}

O comportamento parental é reconhecido pelo cuidado, proteção e educação, voltados para a criança, por meio de um conjunto de ações, caracterizado por crenças e práticas que denotam o que os pais pensam sobre as formas de cuidado e criação dos fiIhos. O modo como os pais cuidam de seus filhos, as estratégias utilizadas no cuidado infantil, as interações mantidas, as ações realizadas estão em consonância com ideias (crenças, atribuições, inferências, atitudes, conhecimentos, opiniões, valores e metas) e sentimentos (afetos, emoções) parentais em relação à socialização e ao desenvolvimento infantil ${ }^{1}$.

Há um consenso entre diversos pesquisadores ${ }^{2,3}$ de que as crenças parentais são influenciadoras das práticas de cuidado e comportamentos dos pais, podendo gerar efeitos diversos sobre o comportamento das crianças e o desenvolvimento infantil. Contudo, embora as práticas parentais estejam associadas às suas crenças, não há uma relação direta de causa e efeito entre elas, uma vez que as crenças são construídas nas relações sociais e estas interferem na maneira de agir das pessoas, o que pode gerar uma inconsistência entre o que se pensa e o que se faz ${ }^{2}$.

Harkness e Super ${ }^{3}$ propuseram o conceito de nicho desenvolvimental como ferramenta para analisar a estrutura cultural do desenvolvimento infantil. O modelo é estruturado em um sistema composto por três subsistemas interligados, que se coordenam no tempo e permeiam as trajetórias desenvolvimentais humanas: o ambiente físico e social, que corresponde ao tipo de casa que a criança vive e a organização social familiar em que está inserida; as práticas de cuidado e educação da criança, ligada à criação e práticas educativas culturalmente determinadas; e as etnoteorias parentais (psicologia dos cuidadores), que são modelos culturais que representam crenças e valores que os pais têm sobre crianças e famílias e concepções sobre como os filhos devem ser criados ${ }^{3}$.
A psicologia dos cuidadores em contextos não familiares se apresenta como um campo relativamente novo para pesquisa e desperta a atenção dos que se dedicam à investigação dos processos de socialização primária e trajetórias desenvolvimentais na infância. As publicações sobre o tema são incomuns quando comparadas ao evidente interesse na contemporaneidade pela maneira como os pais educam e cuidam dos filhos ${ }^{4}$. Esse dado sustenta a hipótese de que, em número mais reduzido, estejam pesquisas que investigam aspectos da psicologia dos educadores de abrigo, uma vez que a literatura sobre essa modalidade de cuidado infantil é recente ${ }^{5}$.

Se, por um lado, a expressão educador de abrigo parece nova no meio acadêmico e social, uma vez que acompanha a constituição dos primeiros abrigos para crianças e adolescentes no Brasil, em conformidade com os princípios definidos pelo Estatuto da Criança e do Adolescente (ECA $)^{6}$; por outro, surge tão antiga quanto atual, uma vez que remete à imagem de profissionais responsáveis por uma forma específica de cuidado substituto, o acolhimento institucional, que atende crianças privadas do cuidado parental ou que mantém vínculos frágeis com seus pais e/ou responsáveis.

Isso significa que o que pensa o educador de abrigo acerca da criança, alvo do trabalho que realiza na instituição, remonta imagens e concepções que trazem as marcas de uma longa história de assistência caritativa à infância desvalida à época da Roda dos Expostos, da atenção aos pobres e abandonados em antigas instituições de bem-estar do menor e, por fim, nas últimas décadas, do acolhimento provisório da criança como medida de proteção especial em razão da sua condição de sujeito de direitos ${ }^{7,8}$.

Desse modo, percebe-se que mesmo com todo o esforço para a propagação dos princípios éticos e políticos contidos no $\mathrm{ECA}^{5}$, ainda persiste a imagem da infância em risco como uma ameaça que se volta contra a própria sociedade e que de algum modo representa problema às pessoas que estão ao seu re- 
dor. Mesmo que situações de comoção sejam comuns diante da permanência prolongada de crianças em acolhimento institucional, no cotidiano, a imagem que a sociedade constrói acerca da sua condição psicossocial ainda se apresenta revestida de equívocos, medos e preconceitos. Em outras palavras, quem são e como vivem as crianças acolhidas em abrigos, do ponto de vista do profissional responsável pelo seu cuidado diário, é uma questão posta para o debate. Talvez o conjunto das respostas obtidas contribua para esclarecer aspectos que são subjacentes ao cuidado institucional de crianças em situação de risco, bem como fornecer subsídios para a construção de um projeto político pedagógico que leve em consideração a maneira como os educadores concebem a história e o desenvolvimento das crianças em acolhimento institucional.

Nesses termos, a visão dos educadores de abrigo sobre quem é a criança acolhida nesse tipo de instituição deve guardar grau de concordância com um conjunto de crenças historicamente associadas à condição psicossocial da criança institucionalizada. Essas crenças são aqui reconhecidas como ideias que há tempos povoam o imaginário social e remetem à população dos antigos orfanatos e berçários públicos ${ }^{7,8,9}$, ilustram a literatura antiga e atual sobre o tema da privação dos cuidados maternos ou mesmo parentais ${ }^{10,11}$ e embasam discursos sobre a condição de grave vulnerabilidade social e emocional da criança institucionalizada ${ }^{12}$.

Sobre a questão, achados de pesquisas ${ }^{4,13,14}$ revelam que os estudos sobre crenças de educadores de creche acerca de aspectos relacionados ao desenvolvimento humano podem ser úteis para a implementação de políticas e programas de educação infantil que sejam mais sensíveis às condições em que esses profissionais realizam o seu trabaIho. O mesmo raciocínio pode ser aplicado para recuperar o quão relevantes podem ser os conhecimentos que incluem a percepção que os educadores de abrigo têm sobre os limites e as oportunidades colocadas por seu trabalho, no sen- tido de promover o bem-estar da criança e o seu desenvolvimento.

Para tanto, entende-se ser necessário conhecer bem as condições em que os educadores realizam o seu trabalho na instituição e o que pensam sobre o desenvolvimento da criança que sofre a influência direta ou indireta das suas práticas de cuidado e educação. Assim, este estudo tem como objetivo analisar a percepção de educadores de abrigo acerca do trabalho desenvolvido por eles e sobre as crianças em acolhimento institucional.

\section{MÉTODO}

\section{Participantes}

Fizeram parte do estudo 102 educadores, funcionários de uma instituição de abrigo, no período de 2004 a 2006. As participantes representam $83,61 \%$ do quadro de funcionários nessa função. Toda a amostra pertence ao sexo feminino $(100 \%)$, com no máximo 35 anos de idade $(61,76 \%)$ e possuem filhos $(54,91 \%)$. Mais de a metade das educadoras $(55,86 \%)$ já concluiu ou frequenta curso de nível superior, dentre elas seis cursos de formação aparecem: pedagogia $(53,84 \%)$, licenciatura $(26,96 \%)$, serviço social $(7,69 \%)$, nutrição $(3,84 \%)$, psicologia $(3,84 \%)$ e sociologia(3,84\%).

Por se tratar de uma amostra formada basicamente por mulheres, com variações referentes à idade e à escolaridade, optou-se por utilizar o termo educadoras de abrigo, ou ainda, quando se quis relacionar as percepções levantadas pela pesquisa a variáveis como idade, utilizaram-se expressões como educadoras com menos de 30 anos (para identificar as mais novas) e educadoras com mais 30 anos (para indicar as mais veIhas). A escolha para esta faixa etária se deu em função da maior distribuição das educadoras em dois grupos etários: de 20 a 30 anos (45,10\%), de 31 anos em diante $(43,14 \%)$, sendo neste grupo somadas aquelas com mais de 40 anos $(11,76 \%)$. Ressalta-se que as educadoras com menos idade também são aquelas com menor tempo de trabalho na ins- 
tituição, um ano ou menos de tempo de serviço $(42,15 \%)$.

\section{Ambiente}

$O$ estudo foi realizado em uma instituição destinada ao acolhimento de crianças em situação de vulnerabilidade social, na faixa etária de zero a seis anos. O abrigo é considerado um serviço de alta complexidade que integra o Sistema Único de Assistência Social (SUAS), sendo o maior e o mais antigo abrigo infantil da Região Metropolitana de Belém, no norte do país. Atualmente a instituição acoIhe, em média, 50 crianças, incluindo os bebês, mas, com frequência, atende 70 a 80 , entre meninos e meninas.

Por ser uma entidade de direito público integrante da administração direta do Governo do Estado do Pará, vinculado à Secretaria de Estado e Desenvolvimento Social (SEDES), a seleção dos profissionais, incluindo-se os educadores, se dá mediante concurso publico.

\section{Instrumentos e materiais}

Foi utilizado o questionário criado por Ongari e Molina15, adaptado às características do contexto de pesquisa em abrigo. Foram incluídas questões relativas ao trabalho do educador em instituição de abrigo, assim como perguntas que tratam das especificidades dessa modalidade de cuidado infantil.

$O$ instrumento apresenta perguntas abertas e fechadas, organizadas em torno de categorias como características sociodemográficas dos educadores e dados da sua história pessoal, profissional e institucional. Em sua maioria, as questões apresentam variáveis cujo nível de medida estatística é nominal. O questionário traz, contudo, questões que pressupõem o trato de outras medidas estatísticas, como a ordinal e a intervalar. Por meio de escala do tipo Likert (1 a 5 pontos - de discordo a concordo completamente), pretendeu-se aferir o nível de concordância do entrevistado com assertivas que traduzem várias das percepções que estão presentes na literatura que discute a condição psicossocial da criança institucionalizada, além de ideias e crenças relaciona- das ao tema que se mantêm presentes na sociedade atual.

\section{Procedimento}

Por se tratar de instituição destinada à guarda de crianças afastadas do convívio familiar, foi necessária a obtenção da autorização judicial para realização da pesquisa. No momento seguinte, o projeto foi submetido ao exame do Comitê de Ética em Pesquisas com Seres Humanos do Núcleo de Medicina Tropical da Universidade Federal do Pará, que aprovou a proposta do estudo, sem objeção ou alteração no texto (Protocolo $n^{\circ}$ 062/2004 - CEP/MMT, assinado em 08/ 09/2004).

A fase da coleta de dados teve início com a aplicação do questionário pela pesquisadora com os educadores do abrigo, sendo realizada de acordo com a data e o horário do plantão. As perguntas foram feitas verbalmente, mas as respostas dadas pelas educadoras eram registradas pelo pesquisador em espaço no questionário previsto para esse fim.

Os dados coletados a partir do uso da aplicação do instrumento foram codificados e lançados em planilhas eletrônicas elaboradas através do programa Excel, versão 2007. A análise estatística foi realizada a partir do cálculo de frequências e percentagens e as figuras geradas para apresentação dos resultados obtidos a partir do cálculo de frequência simples e acumulada.

\section{RESULTADOS E DISCUSSÃO}

\section{Percepções das educadoras acerca da criança em acolhimento institucional}

Os resultados referentes às variáveis investigadas descrevem traços da percepção que as educadoras têm acerca dessa modalidade de cuidado infantil e seus efeitos para o desenvolvimento da criança deixada sob seus cuidados na instituição. Isso significa perceber as condições objetivas e subjetivas em que se materializam as práticas de cuidado infantil nesse ambiente e ter elementos 
para pensar o nicho de desenvolvimento da criança institucionalizada ${ }^{3}$.

As percepções levantadas foram organizadas em torno de seis eixos: 1) condição sociofamiliar; 2) atenção às necessidades essenciais; 3 ) características do ambiente de convivência; 4) interação e relação com os adultos; 5 ) interação e relação com as crianças; e 6) efeitos da institucionalização.

Os resultados a seguir mostram a posição das educadoras quanto ao grau de concordância com ideias e crenças historicamente associadas à condição psicossocial da criança institucionalizada. Ao investigar o percentual de concordância das educadoras com assertivas reunidas em torno da condição sociofamiliar da criança que vive em instituição, encontrou-se que praticamente a metade concorda com a afirmação de que as crianças encaminhadas ao abrigo têm família $(50,98 \%)$. Para elas, na maioria das vezes, as crianças têm referência familiar e mantêm algum tipo de ligação com a família de origem, razão pela qual os pais as visitam no espaço, mesmo que eventualmente. Essa percepção, contudo, está mais presente entre as educadoras com mais de 30 anos, provavelmente em função das inúmeras crianças que já tiveram a oportunidade de ver deixarem o abrigo e retornarem ao convívio com seus genitores, tão logo foram atendidas as suas necessidades mais prementes.

De fato, ao contrário do que parece estar cristalizado no imaginário social, muitas crianças têm sido afastadas do lar e privadas do convívio com seus pais, ainda que possuam referência familiar e os responsáveis tenham paradeiro conhecido ${ }^{5,16}$.

Na região norte, quase $89 \%$ das crianças e adolescentes que estão em abrigos tem família contra $86,7 \%$ em todo o país ${ }^{16}$. Os números referentes à região indicam ainda que $58,9 \%$ das crianças e dos adolescentes que vivem em abrigos têm família e mantêm vínculo com seus pais e/ou parentes próximos, o que, em tese, deveria ser um elemento facilitador do seu processo de retorno ao convívio com a família de origem.
No que se refere à imagem da criança institucionalizada como aquela que tem sua origem familiar ligada à pobreza, essa não é propriamente uma ideia corrente entre educadoras de forma geral (mais e menos de 30 anos), a pobreza não poderia ser tomada como fator que em si mesmo consegue explicar a quantidade de crianças que todos os meses são encaminhadas à instituição para acolhimento provisório. Para elas, existem hoje milhares de crianças pobres que conseguem ser cuidadas por seus pais biológicos, ficando a salvo de situações de risco como a violência doméstica e o abandono. Por isso, a maioria não concorda com a ideia de que a pobreza possa servir como argumento capaz de justificar a colocação da criança em abrigo. Entretanto estudos recentes sobre o perfil da população de crianças e adolescentes que povoam as instituições de abrigo no Brasil indicam que a pobreza continua a se constituir em motivo (por vezes, o único ou o mais relevante) para a privação do convívio com a família ${ }^{16}$.

Mais da metade das educadoras $(87,26 \%)$, independentemente da idade, concordam com a ideia de que a criança institucionalizada foi afastada do convívio com a família, em um momento especialmente importante da sua trajetória de desenvolvimento. Percebe-se que esse resultado possivelmente reflete 0 fato de que hoje há uma maior difusão de informações acerca do desenvolvimento infantil e do valor do convívio com a família, no processo de socialização primária da criança e formação do apego. Esse acesso à informação pode ocorrer não apenas em atividades de capacitação profissional, mas inclusive por meio da mídia e outros meios que procuram demonstrar o quanto pode ser nociva a separação ou a perda para a criança da figura dos pais e demais familiares, mesmo quando o distanciamento é temporário ${ }^{17,18}$.

No que tange à oportunidade de satisfação das necessidades essenciais da criança pelo abrigo, a maioria das educadoras considera que o cuidado com a alimentação, sono, higiene e segurança física são suficientemente garantidos pela 
instituição (90,2\%). Entretanto, mais de $70 \%$ indicaram a impossibilidade da criança encontrar no abrigo um ambiente capaz de estimulá-la do ponto de vista intelectual.

Esses dados mostram-se reveladores, à medida que ilustram o quão distante está a materialização de uma concepção de cuidado institucional que prevê o atendimento integral às necessidades da criança em situação de vulnerabilidade física, emocional e social, como estabelecem as Orientações Técnicas para Serviços de Acolhimento para Crianças e Adolescentes, elaborado pelo Ministério do Desenvolvimento Social e Combate à Fome $^{19}$. De novo prevalece a ideia de que as instituições infantis estão destinadas a zelar pela criança de forma integral, porém, na prática, segundo as educadoras, incubem-se dos cuidados que asseguram a sobrevivência física, mas não em termos do seu desenvolvimento como ser social e intelectual.

Aqui, resgata-se a discussão sobre a pseudoprimazia da educação sobre o cuidado, como mostram trabalhos sobre o assunto. As instituições infantis no passado, especialmente as creches, eram vistas como serviço público ou comunitário destinado a guardar as crianças, cujos pais, por alguma razão, não podiam fazê-lo de maneira adequada13-15,20-21. Nos dias atuais, cresce a consciência de que esse tipo de instituição requer para seu funcionamento ações que associem o cuidar e o educar. Da mesma forma, entende-se que os abrigos, como instituições infantis, precisam estar em sintonia com fato de que não deve existir uma sobreposição do cuidar sobre o educar. As duas ações precisam ser concomitantes, procurando resguardar o interesse superior da criança institucionalizada, qual seja assegurar condições favoráveis ao desenvolvimento das suas potencialidades humanas ${ }^{22}$.

No tocante a percepção das educadoras acerca das características do ambiente institucional, observa-se que dois terços das educadoras concordam que a criança institucionalizada vive em condições contextuais pouco favoráveis à liberdade de fazer escolhas sobre questões práticas do seu dia-a-dia (72,55\%), ou mesmo, sem o direito a gozar de espaço pessoal e privacidade $(66,67 \%)$, tal qual o exposto na figura 1.

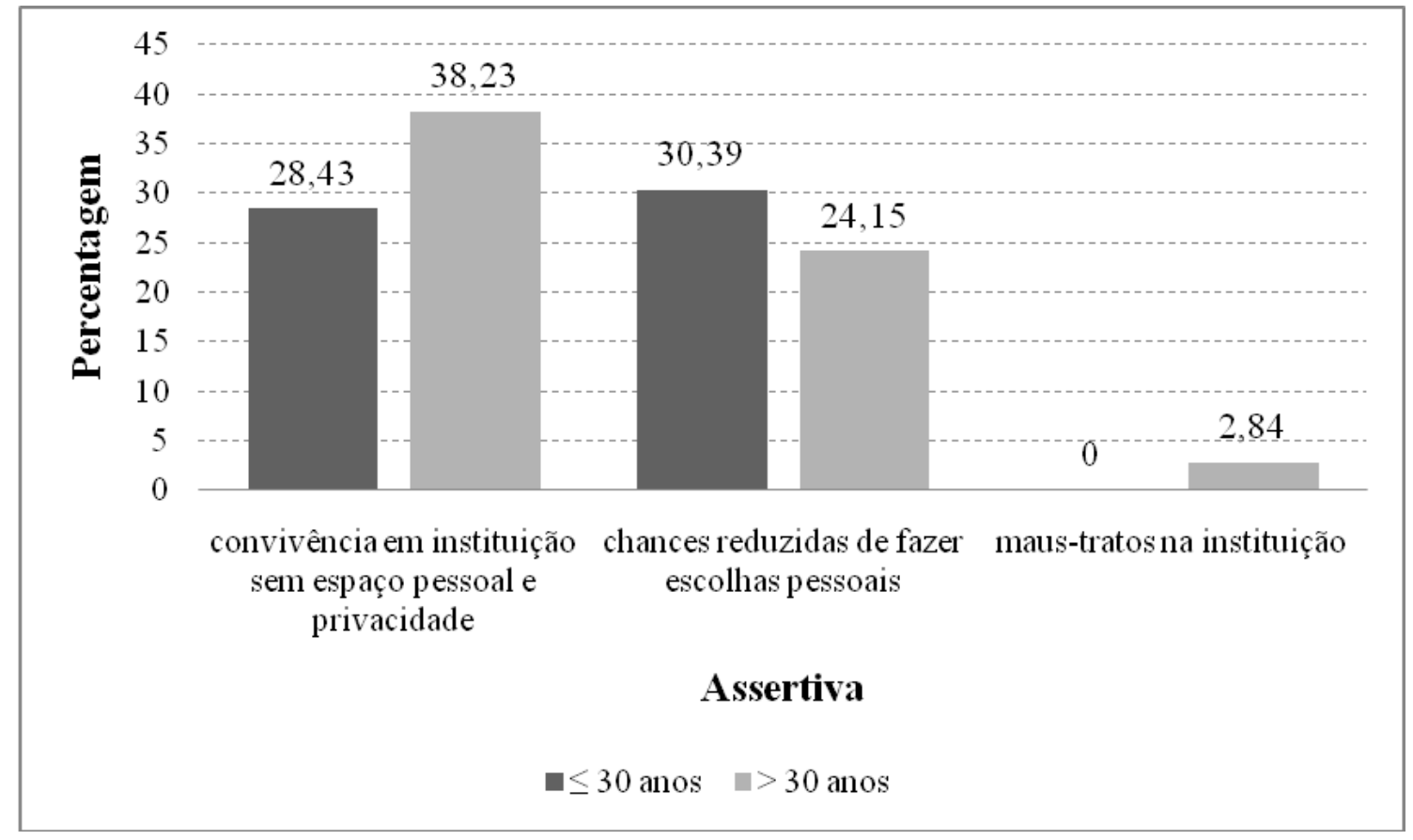

Figura 1: Porcentagem de educadores por concordância com assertivas sobre características do ambiente social onde vive a criança institucionalizada, segundo idade. 
Todavia, a percepção sobre a presença de características ambientais que são típicas da vida em instituições fechadas ou asilares parece ser mais evidente entre as educadoras que estão acima dos 30 anos. Fica a hipótese de que a maturidade e o acúmulo de experiência no trato com a infância conferem a essas profissionais uma maior sensibilidade quanto à noção do que é intimo e pessoal na estruturação da personalidade do indivíduo ${ }^{23}$. Em estudo realizado, ao discutirem as diferenças entre o cuidado coletivo oferecido em instituições e residências e o cuidado individual nas famílias substitutas, Roy, Rutter e Pickles ${ }^{23}$ encontraram que as crianças que receberam cuidado individual em lares adotivos, mesmo com histórico de institucionalização precoce, apresentaram melhor desempenho em termo das habilidades mensuradas ${ }^{23}$. Diferentemente das que haviam recebido atendimento grupal, mesmo convivendo em instituições residenciais (onde o acolhimento ocorre em ambiente que reedita características dos lares familiares), tal qual as que residiam em instituições asilares tradicionais, o que demonstra ser decisiva a forma como a criança com histórico de privação do cuidado parental é tratada em seu ambiente imediato, durante e após a institucionalização.

Por sua vez observa-se que um percentual baixo de educadoras (3,92\%) concebe a existência de maus tratos nas dependências das instituições de abrigo. Na opinião da maior parte das educadoras, essa não é uma assertiva verdadeira, uma vez que as crianças podem até não receber todos os cuidados necessários ao seu bem-estar físico e emocional, contudo não chegam propriamente a serem maltratadas no interior da instituição, uma vez que dizem desconhecer registros de punições físicas por parte de qualquer funcionário, além de outras formas de exploração do seu trabalho ou até de negligência com a sua saúde e segurança, como frequentemente parece acontecer no convívio com a família de origem.

Ao analisar os percentuais de concordância com assertivas em torno de aspectos da dinâmica de interação da criança com adultos na instituição, percebe-se que, pelo conteúdo das respostas às questões formuladas, a maioria das educadoras considera que a criança não recebe no abrigo atenção individualizada, posto que a preocupação com o cumprimento das tarefas, que envolvem o cuidado diário de crianças em diferentes faixas etárias e condição psicológica, faz com que a educadora não crie momentos para tratar cada criança como um ser único, respeitadas em suas particularidades, na hora de vesti-la após o banho, de alimentá-la no refeitório, de motivar a sua participação em determinadas atividades $^{24}$.

Nesses momentos, contrariando 0 que tem sido dito por teóricos do desenvolvimento humano ${ }^{3,25}$, percebe-se que muitos educadores secundarizam o valor desse conhecimento e o quanto poderia facilitar o convívio uns com os outros e inclusive potencializar o que reúnem de especial em sua subjetividade.

Em seus estudos, autores ${ }^{15,20,21}$ afirmam ainda que, nas instituições infantis, as atividades se repetem, porém não se realizam da mesma forma para cada criança. Nesses termos, alertam que as atividades se repetem dia após dia, mas não as crianças. Elas são seres únicos que vivenciam as atividades de maneira singular e assim devem ser reconhecidas.

As educadoras (quase $90 \%$ ) partiIham da crença de que a criança institucionalizada mantém no abrigo relações pouco estáveis e duradouras com adultos, que frequentemente são educadores, mas também podem ser técnicos, encarregados de serviços gerais, visitantes, voluntários, dentre outros.

Há tempos atrás, era hegemônica a ideia de que crianças cuidadas fora do lar e em ambiente coletivo mantinham com vários adultos uma multiplicidade de relações sociais e afetivas que ao final traria prejuízos ao seu desenvolvimento ${ }^{13-15,20-21}$. No entanto, estudos mais recentes estão questionando essa forma de pensar, mostrando que a criança que é cuidada em ambiente coletivo, como as creches, por exemplo, aprende a tirar proveito dessas múltiplas experiências de 
interação e envolvimento, que os laços afetivos podem ser vários, sem que isso acarrete transtornos ao seu amadurecimento emocional.

No caso das instituições de abrigo, o relacionamento com os educadores e outros adultos muitas vezes não tem apenas caráter complementar, como acontece com as crianças cuidadas em creche e pré-escola, ainda que em tempo integral. No ambiente institucional, a relação com os educadores assume contornos mais complexos, uma vez que a criança, algumas vezes, não chegou a constituir figuras de referência no convívio com a família, nem na interação com seus cuidadores em ambientes substitutos ${ }^{26,27}$.

Outro aspecto que precisa ser ressaltado diz respeito ao fato de que o maior percentual de concordância entre as educadoras está relacionado à constatação de que a criança institucionalizada disputa constantemente a atenção da educadora com outros abrigados $(92,16 \%)$, posto que a proporção entre adultos e crianças e, em alguns casos, a superlotação das instituições, pode tornar precária a atenção dispensada por esses cuidadores, especialmente quando envolve a lida com bebês.

Quando se toma para análise o que pensam as educadoras sobre o modo como se estabelece a interação criançacriança no ambiente institucional e as particularidades dessa forma de relacionamento social, verifica-se que $89,21 \%$ avaliam ser verdadeira a assertiva que se reporta à forte influência exercida pelo grupo de pares sobre o comportamento da criança. Em condições normais, acreditam que o grupo exerce grande influência sobre o modo de pensar e agir do indivíduo. No caso das crianças em geral, mais especialmente daquelas que coabitam na instituição, o poder de ditar comportamentos e atitudes deve-se à força que tem o aprendizado pela imitação nessa idade, à proximidade física que facilita a coesão grupal e às estratégias de ajustamento social do indivíduo, sob pena de sucumbir às pressões do meio em que se insere.

Os resultados indicam que o número de educadoras que considera ser pos- sível - e até comum - à criança institucionalizada, construir relações estáveis e duradouras com coetâneos representa $38,23 \%$. Essa parcela das educadoras concorda com a ideia de que a intensa convivência entre coetâneos no cotidiano da instituição pode levar à formação de laços afetivos caracterizados pela amizade e o sentimento de apego entre pares preferenciais.

Sobre a questão, diversos autores ${ }^{13-15,20-21}$ reconhecem ser vantajoso para a criança ter a sua socialização primária associada ao convívio em instituições infantis, basicamente as creches e as escolas, posto que muitas são as alternativas de companhia e parceiros de interação nesses ambientes de cuidado coletivo. Entretanto, no que diz respeito à convivência entre coetâneos no cotidiano dos abrigos, estudos mostram que a interação criança-criança não apenas é importante, como necessária ao seu completo bem-estar. $\mathrm{Na}$ falta de adultos com quem possa estabelecer ligações afetivas fortes e duradouras, a criança institucionalizada tende a buscar entre seus semelhantes companhia, conforto e segurança emocional ${ }^{5,9,26}$.

Outro feixe de categorias a ser comentado diz respeito aos efeitos da institucionalização reconhecidos pelas educadoras como elementos presentes no universo dos abrigos para crianças. A figura 2 mostra que o grau de concordância com as possíveis sequelas colocadas ao desenvolvimento por uma infância passada longe de casa, não faz dessas assertivas pontos pacíficos na discussão sobre a institucionalização de crianças. Nem mesmo, no caso em que esse efeito se reveste de uma aura positiva, como quando remete à ideia de que a criança institucionalizada apresenta capacidade acentuada para se adaptar facilmente a situações novas e estranhas.

Entre as educadoras existe a percepção de que tem sido frequente a presença de crianças institucionalizadas que se comportam de maneira agressiva, tanto com adultos quanto com seus pares $(71,57 \%)$. Igualmente, $47,06 \%$ ressaltam que a institucionalização leva a criança a conviver todos os dias com pessoas 


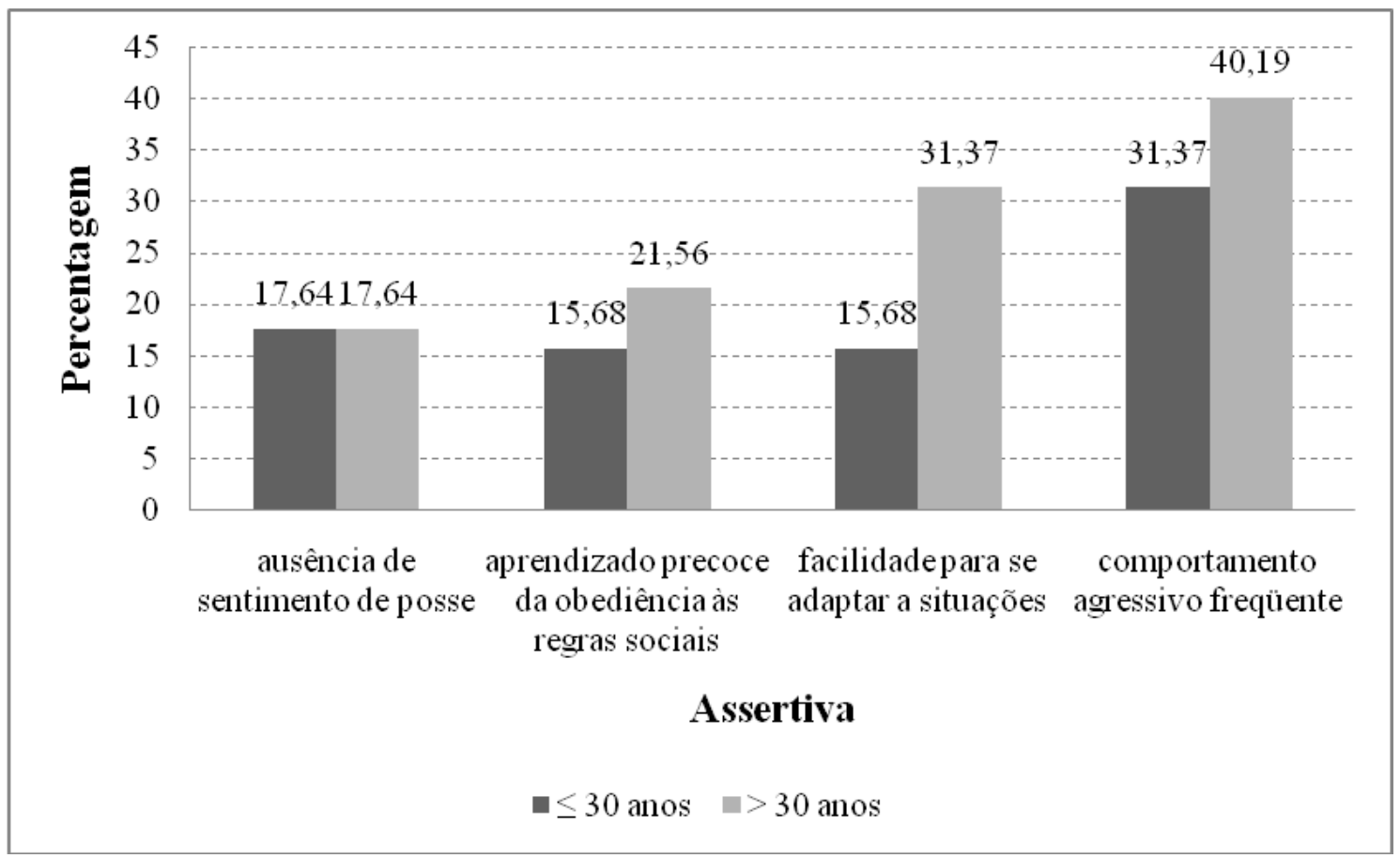

Figura 2: Porcentagem de educadoras por concordância em relação aos efeitos do cuidado em instituição de abrigo para o desenvolvimento da criança, segundo idade.

e experiências muito distintas das que lidavam em casa ou na comunidade de origem. Na forma de ver da maioria, esse tipo de contingência conduz a criança institucionalizada a um comportamento mais flexível em relação à mudança do ambiente e pessoas que ficam em seu entorno.

Embora a sua existência seja reconhecida por especialistas ${ }^{9,17,18}$, o estresse gerado pela imperiosa necessidade de se adequar à realidade apresentada pelo abrigo provém justamente do fato de que a criança institucionalizada acaba por ter que lidar com situações que se revestem de estranhamento e despertam sentimentos de insegurança difíceis de serem aplacados. A criança institucionalizada experimenta, assim, a chamada separação total (noite e dia), sendo muitas vezes levada até a instituição sem qualquer preparo anterior. Em geral deixam um ambiente literalmente familiar e são encaminhadas para o convívio em um meio, à primeira vista, hostil e estranho. Nesse ambiente desconhecido, encontram comumente dificuldade para constituir figuras de referência do ponto de vista afetivo, ou seja, que sirvam como base de segurança para momentos de risco e situações de angústia, medo e raiva. Além disso, com frequência, vivenciam fatos desagradáveis que tornam obrigatória algumas experiências indesejadas, como refeições, banho e sono forçados, sem contar que as interações lúdicas nem sempre são incentivadas pelas educadoras e demais profissionais responsáveis pelo cuidado diário.

\section{Percepções das educadoras acerca do trabalho com crianças institucionalizadas e sua influência sobre o seu desenvolvimento}

A percepção quanto ao trabalho realizado cotidianamente no abrigo difere quanto ao grau de influência que exerce sobre o desenvolvimento da criança em situação de acolhimento institucional. A tabela 1 demonstra o ponto de vista das educadoras acerca do grau de influência que o seu trabalho exerce sobre a aquisição de determinadas habilidades e competências infantis.

As educadoras consideram exercer por meio do seu trabalho forte influência 
Tabela 1: Porcentagem de educadores segundo percepção acerca do grau de influência do trabalho realizado no abrigo para o desenvolvimento da criança.

nenhuma influência pouca influência influência média grande influência

\begin{tabular}{lcccc}
\hline segurança & 0,98 & 5,88 & 27,46 & 65,68 \\
relacionamentos & 0 & 7,84 & 39,22 & 52,94 \\
autonomia & 2,94 & 12,75 & 33,3 & 50,98 \\
cumprimento dos requisitos & 3,92 & 10,78 & 36,28 & 49,02 \\
cooperação & 1,96 & 14,7 & 39,22 & 44,12 \\
curiosidade & 9,8 & 22,54 & 29,42 & 38,24 \\
lógicas e raciocínios & 2,94 & 23,52 & 43,14 & 30,4 \\
controle emocional & 4,9 & 33,33 & 33,33 & 28,44 \\
concenrtração & 3,92 & 36,28 & 38,24 & 21,56 \\
\hline
\end{tabular}

sobre o comportamento das crianças e aspectos decisivos do seu amadurecimento psicológico, especialmente no que se refere à sensação de segurança $(65,68 \%)$, à capacidade de relacionarse com os outros $(52,94 \%)$, à postura de autonomia $(50,98 \%)$, para resgatar apenas as três categorias mais citadas. A soma dos percentuais que correspondem às categorias muita influência e influência suficiente representam mais de dois terços das educadoras, o que significa dizer que é bastante positiva a avaliação que possuem acerca da importância do seu trabalho para o desenvolvimento social, afetivo e cognitivo da criança institucionalizada.

No que se refere à possibilidade do trabalho da educadora influenciar o grau de autonomia experimentado pela criança em diferentes circunstâncias, a criança costuma ser incentivada a exercitar o controle sobre o próprio corpo e funções vitais (ir ao banheiro, alimentar-se, banhar-se) e a participar de atividades que propiciam o treino de habilidades motoras, cognitivas e até lúdicas ${ }^{14}$.

Por sua vez, as educadoras entendem que exercem pouca ou nenhuma influência sobre o despertar na criança da curiosidade para explorar o meio ambiente $(32,34 \%)$, o desenvolvimento de competências lógicas e de raciocínio $(32,46 \%)$ e o saber lidar com as emoções $(38,23 \%)$. Entretanto, no que se refere ao controle das emoções, as mesmas alegam que essa capacidade aprimorada não depende somente do trabaIho desenvolvido pelos educadores, mas, sobretudo, do fato de que a criança se encontra longe do convívio com a família e emocionalmente perturbada por essa situação.

Quanto à capacidade de controle das emoções, entendem ser tarefa difícil até mesmo para o adulto, quanto mais para a criança em situação de sofrimento emocional. Nesse contexto, entendem que as crianças estranham a necessidade de rígido ajustamento social às regras colocadas pela vida institucional e sua dinâmica própria, por ser muito distinta do meio familiar ou mesmo da que percebe em outras instituições infantis ${ }^{25}$. O exercício do controle de emoções básicas como a raiva e o medo em situações estranhas à criança não é tarefa das mais fáceis e exige grande preparo e segurança por parte do educador nesse tipo de manejo.

Entre os aspectos do desenvolvimento com menor poder de influência dos educadores, estaria a aquisição de certas habilidades cognitivas, provavelmen- 
te porque, como fazem questão de frisar, seriam poucas as chances de realizarem um trabalho de natureza pedagógica no abrigo, que vise ao aprendizado de conhecimentos e valores socialmente definidos. As educadoras consideram que têm pouca ingerência sobre esse aspecto do desenvolvimento, já que o associam de maneira quase exclusiva às atividades pedagógicas, que contam normalmente com restrita participação das educadoras na sua organização e condução.

Os resultados mostram ainda que apenas $16,66 \%$ avaliam que o trabalho da educadora exerce pouca $(1,36 \%)$ ou nenhuma influência $(14,7 \%)$ sobre a aquisição de habilidades sociais, que se traduzem por atitudes de empatia e pelo cuidado da criança com outra igual. $\mathrm{Na}$ verdade, entendem que a tarefa de estimular a criança a se sentir disposta a colaborar com seus pares não pode ser de responsabilidade exclusiva do educador, mas não resta dúvida que, dadas as circunstâncias em que convive, esse profissional ocupa lugar de destaque em seu processo de socialização primária.

A literatura mostra que trabalho do educador pode levar a criança no ambiente institucional a colaborar com o outro de diferentes formas: cooperando em ações que apresentam maior grau de dificuldade, socorrendo o colega em situações de risco ou conflitos, compartiIhando objetos ou alimentos numa demonstração de apreço pelo parceiro ${ }^{28}$.

Somando-se a isso, as instituições que acolhem crianças, principalmente as do tipo residencial, podem motivar as crianças a compartilharem tarefas e a cooperarem entre si e com os funcionários $^{11}$. Esse tipo de atitude por parte dos educadores pode contribuir na prevenção de efeitos traumáticos gerados pela convivência, precoce e prolongada, em instituições asilares ${ }^{11}$.

Com os resultados apresentados neste artigo, procurou-se valorizar a discussão acerca da psicologia das educadoras no contexto do abrigo, que inclui ideias e crenças acerca da condição psicossocial da criança e da influência do trabalho realizado na instituição para o desenvolvimento infantil.

Ao investigar a literatura, identificou-se que o papel do cuidador para o desenvolvimento infantil, sobretudo no que diz respeito às suas concepções, crenças e ideias sobre desenvolvimento, vem sendo amplamente discutido. Essa busca recente reflete as contribuições trazidas por Harkness e Super ${ }^{3}$, no sentido de motivar as ciências do desenvolvimento humano a expandirem seu campo de atuação sobre ideias, convicções, valores e expectativas que traduzem 0 modo como os cuidadores primários, em distintos contextos sociais e culturais, pensam as potencialidades da criança. No entanto, apesar do crescente interesse, pesquisas que tomam os cuidadores profissionais de instituições de abrigo como objeto de estudo, sua psicologia e suas práticas, ainda são insipientes.

Neste estudo, o uso do questionário possibilitou conhecer o perfil dos educadores responsáveis pelos cuidados das crianças no abrigo, bem como a sua percepção acerca da condição psicossocial da criança institucionalizada e as implicações do trabalho que realiza no abrigo para o desenvolvimento infantil.

Os dados da pesquisa revelaram que as educadoras, em sua maioria, compartilham a opinião de que as crianças abrigadas têm um atendimento satisfatório da instituição com a alimentação, sono, higiene e segurança física, no entanto as questões de ordem afetiva e intelectual ficam em aberto. Tais resultados reforçam a ideia de que os cuidados no abrigo estão relacionados à sobrevivência física da criança e não ao seu desenvolvimento como ser social e intelectual.

Um achado interessante refere-se ao fato de que as educadoras consideram que a criança institucionalizada vive em condições contextuais pouco favoráveis à liberdade de fazer escolhas sobre questões práticas do cotidiano ou mesmo sem o direito de gozar de espaço pessoal e privacidade, não recebendo no abrigo uma atenção individualizada. Esta é uma questão que merece destaque, uma vez que se acredita que os valores 
e crenças compartilhados pelos cuidadores sobre o desenvolvimento infantil influenciam seu comportamento e suas práticas, além de afetar as interações com as crianças.

Somando-se a isso, as educadoras corroboram a ideia de que a criança mantém no abrigo relações pouco estáveis e duradouras com os adultos, mas que apesar disso há uma busca constante de atenção da educadora com outras crianças do abrigo. Elas consideram ainda que há uma forte influência do grupo de pares sobre o comportamento da criança e somente um terço delas podem ter vinculação entre si.

No que diz respeito ao seu trabaIho na instituição, as educadoras acreditam exercer pouca influência sobre o desenvolvimento cognitivo e afetivo da criança, destinando esse aspecto às atividades de natureza pedagógica, o que mostra a dicotomia entre cuidar e educar, ainda presente na visão das educadoras. Tal fato confirma a crença de que a revisão das concepções de criança e de seu desenvolvimento é ação prioritária no enfrentamento do problema.

Os dados da pesquisa sugerem investimento na formação inicial e na capacitação continuada dos cuidadores, medidas que poderiam fazer a diferença no cuidado dispensado às crianças. As orientações técnicas para o acolhimento de crianças e adolescentes ${ }^{19}$ reforçam a ideia de que para exercer sua função, o educador deve ter capacitação adequada para desempenhar seu papel com autonomia e ser reconhecido como figura de autoridade para a criança, bem como deve receber apoio e orientação permanente e ter espaço para trocas, nos quais possam compartilhar experiências

\section{REFERÊNCIAS}

1. Goodnow JJ. Parents' ideas, actions and feelings: models and methods from developmental and social psychology. Child Dev. 1988; 59(1): 286-320.

2. Bandeira TT. Investimento e crenças parentais. In: Seidl-de-Moura ML, Mendes DM, Pessoa LF, organizadores. e angústias decorrentes da atuação, buscando a construção coletiva de estratégias para o enfrentamento de desafios. Entende-se que essas medidas tornamse necessárias, visto que as crenças e práticas dos educadores exercem influência para o desenvolvimento da criança e seus padrões de comportamento. Do ponto de vista das educadoras, a forma como percebem e interagem com a criança no dia-a-dia exerce influência sobre os aspectos decisivos da sua trajetória desenvolvimental.

Novos estudos se fazem necessários tanto no sentido de seguir a linha de investigação apresentada neste trabalho, ou ainda abordar proposições de outras experiências de trabalho que possam adotar diferentes pontos de vista sobre as questões aqui suscitadas; tanto no sentido de aprofundá-las como no de investigar questões pouco ou não discutidas nesse universo temático, como relacionar as características do ambiente físico e social do abrigo com as práticas de cuidado e no contexto do abrigo, estabelecer possíveis relações entre a história de vida dos educadores e suas concepções acerca do desenvolvimento infantil e as práticas de cuidado.

Finalmente, salienta-se que existem inúmeros aspectos que devem ser repensados ou modificados no interior das instituições de abrigo e que não existe instituição perfeita, que não necessite de aprimoramento. Por essa razão, enfatiza-se a necessidade de elaboração de um projeto político pedagógico que seja capaz de melhorar essa realidade e leve em consideração, dentre outras coisas, as crenças dos educadores sobre o desenvolvimento infantil e seu trabalho no abrigo.

Interação Social e Desenvolvimento. Curitiba, CRV; 2009. p. 39-56.

3. Harkness S, Super CM. Cross cultural reasearch in child development: a sample of the sate of the art. Dev Psychol. 1992; 28(1): 622625.

4. Melchiori LB, Biasoli Alves ZM. Crenças de educadores de creche sobre temperamento e desenvolvimento de bebês. Psic.: Teor e Pesq. 2001; 17(1): 285292. 
5. Cavalcante LI. Ecologia do cuidado: interações entre a criança, o ambiente, os adultos e seus pares em instituição de Abrigo. [Tese]. Belém: Universidade Federal do Pará; 2008. 510 p. Doutorado em Teoria e Pesquisa do Comportamento.

6. Brasil. Lei n. 8.069, de 13 de julho de 1990. Dispõe sobre o Estatuto da Criança e do Adolescente. [acesso em 8 jul. 2009]. Brasília, 2009. Disponível em: <http://www.planalto. gov.br/ccivil/LEIS/L8069.htm>.

7. Berger MV, Gracino, ER. Aspectos históricos e educacionais dos abrigos de crianças e adolescentes: a formação do educador e o acompanhamento dos abrigados. Rev Histedbr On-line. 2005; 18 (1), 170-185.

8. Rizzinni I, Rizzinni I. A institucionalização de crianças no Brasil: percurso histórico e desafios do presente. São Paulo: Loyola; 2004.

9. Freud A, Burlinghan D. Meninos sem lar. Rio de Janeiro: Fundo de Cultura; 1960.

10. Siqueira AC, Betts MK, Dell'Aglio DD (2006) A rede de apoio social e afetivo de adolescentes institucionalizados no sul do Brasil. Interam J Psychol.. 2006; 40(2): 149-158.

11. Wolff PH, Fesseha G. The orphans of Eritrea: a five-years a follow-up study. J Child Psychol Psychiatry. 1999; 40(1): 1231-1237.

12. Santana JP, Doninelli TM, Frosi RV, Koller, SH. As instituições de atendimento a jovens em situação de rua segundo a abordagem ecologica do desenvolvimento humano. In: Koller $\mathrm{SH}$, organizador. Ecologia do desenvolovimento: pesquisa e intervenção no Brasil. São Paulo, Casa do Psicólogo; 2004. p. 189-192.

13. Cerisa AB. A construção da identidade dos profissionais na educação infantil: entre o feminino e o profissional. [Tese]. São Paulo: Universidade de São Paulo; 1996. 212p. Doutorado em Educação.

14. Veríssimo MD. O olhar de trabalhadoras de creches sobre o cuidado da criança. [Tese]. São Paulo: Universi- dade de São Paulo; 2001. 200p. Doutorado em Enfermagem.

15. Ongari B, Molina P. A educadora de creche: construindo suas identidades. Ortale FL, Moreira IP, tradutores. São Paulo, Cortez; 2003.

16. Instituto de Pesquisa Econômica Aplicada. Levantamento nacional de abrigos para crianças e adolescentes da rede SAC. [acesso em 06 abr. 2008]. Brasília; 2004. Disponível em: <http://www.ipea.gov.br>.

17. Beckett C, Maughan B, Ruter M, Castle J, Colvert E, Goothues C, et al. Do the effects of early severe deprivation on cognition persist in to early adolescence? from the English and Romanian Adoptees Study. Child Dev., 2006; 77(1), 696-711.

18. Zeanah HC, Nelson CA, Fox NA, Smyke AT, Marshall P, Parker SW, Koga S. Designing research to study the effects of institutionalization on brain and behavior development: the bucharest early intervention project. Dev Psychopathol. 2003; 15(1): 885907.

19. Brasil. Ministério do Desenvolvimento Social e Combate à Fome. Orientações técnicas: serviços de acolhimento para crianças e adolescentes. Brasília: 2009.

20. Bondioli, A. O tempo no cotidiano infantil: perspectivas de pesquisa e estudo de casos. Ortale, FL, Moreira, IP, Tradutores. São Paulo: Cortez; 2004.

21. Gandini L, Edwards C. Bambini: a abordagem italiana à educação infantil. Burguño DA, tradutor. Porto Alegre, Artmed; 2002.

22. Tizard B, Rees J. A comparasion of the effects of adoption, restoration to the natural mother, and continued institutionalization on the cognitive development of four-year-old children. Child Dev. 1974; 45(1): 92-99.

23. Roy $P$, Rutter $M$, Pickles $A$. Institutional care: risk from family background a patern of rearing? J Child Psychol Psychiatry. 2000; 41(1): 139-149.

24. Santos MF, Bastos AC. Padrões de interação entre adolescentes e educadores num espaço institucional: 
ressignificando trejetórias de risco. Psicol Reflex Crit. 2002; 15(1): 2452.

25. Bronfenbrenner U. A ecologia do desenvolvimento humano: experimentos naturais e planejados. Veronese, MA, tradutor. Porto Alegre: Artmed; 2005.

26. Alexandre D, Vieira M. Relação de apego entre crianças institucionalizadas que vivem em situação de abri- go. Psicol. estud. 2004; 9(1), 20717.

27. Nogueira PC. A criança em situação de abrigamento: reparação ou reabandono. [Dissertação]. Distrito Federal: Universidade de Brasília; 2004. 160p. Mestrado em Psicologia Clínica.

28. Kallioupuska. Grouping of children's helping behavior. Psychol Rep. 1992; 71 (1): 747-753. 